\title{
Blockade of the mTOR signaling pathway with rapamycin ameliorates aristolochic acid nephropathy
}

\author{
MINMIN WU ${ }^{1 *}$, LILI TANG $^{2 *}$, BICHENG CHEN $^{1}$, JIANJIAN ZHENG $^{1}$, \\ FENGQUAN DONG ${ }^{3}$, ZHEN SU ${ }^{1}$ and FAN LIN ${ }^{1,3}$ \\ ${ }^{1}$ Key Laboratory of Diagnosis and Treatment of Severe Hepato-Pancreatic Diseases of Zhejiang Province, \\ The First Affiliated Hospital of Wenzhou Medical University, Wenzhou, Zhejiang 325000; ${ }^{2}$ Clinical Laboratory, \\ Chinese Medical Hospital of Jining, Jining, Shandong 272037; ${ }^{3}$ Department of Nephrology, \\ Shenzhen University General Hospital, Shenzhen, Guangdong 518055, P.R. China
}

Received May 4, 2019; Accepted December 3, 2019

DOI: $10.3892 /$ etm.2020.8550

\begin{abstract}
Chronic aristolochic acid nephropathy (CAAN) is characterized by widespread apoptosis and interstitial fibrosis, which severely impairs kidney function. mTOR is crucial for cell proliferation and protein synthesis. In the present study, the therapeutic effects of blockade of mTOR activity by rapamycin on aristolochic acid nephropathy were investigated. In vitro experiments to determine cell apoptosis and cell cycle alterations caused by aristolochic acid (AA)-induced injury were conducted on three groups of cells: Untreated control, AAI (treated with aristolochic acid $\mathrm{I})$, and AAI + rapamycin (RMS). In vivo experiments were conducted in a CAAN mouse model. One group of mice was treated with AAI (the CAAN group), while another group was treated with AAI and rapamycin (the treatment group). Kidney function and pathological changes in these mice were assessed by serum creatinine and urea nitrogen analysis. Hematoxylin and eosin staining of renal tissue was performed to evaluate the treatment effects of rapamycin. Western blotting and immunohistochemical staining were used to explore the mechanisms by which rapamycin inhibited cell proliferation, apoptosis and tissue fibrosis. In the in vitro experiments, rapamycin prevented AAI-induced cell apoptosis and $\mathrm{G}_{2} / \mathrm{M}$ checkpoint cell cycle arrest. In the in vivo experiments, the treatment group exhibited lower serum creatinine and urea nitrogen, less extensive tubular atrophy and increased amount of glomerulus. Additionally, western blotting and immunohistochemical staining showed that the treatment group exhibited
\end{abstract}

Correspondence to: Dr Fan Lin, Department of Nephrology, Shenzhen University General Hospital, 1098 Xueyuan Road, Shenzhen, Guangdong 518055, P.R. China

E-mail: 13867710890@163.com

*Contributed equally

Key words: aristolochic acid nephropathy, mTOR signaling pathway, rapamycin, apoptosis, proliferation, interstitial fibrosis decreased expression levels of fibrosis-, proliferation- and apoptosis-related proteins compared with the CAAN group. The findings suggest that rapamycin can ameliorate kidney injury induced by AAI via blockade of mTOR, and thus could be a therapeutic strategy for patients with CAAN.

\section{Introduction}

Aristolochic acid (AA) is present in Aristolochia plants and used in several types of traditional Chinese medicine. In total, 99 types of AA exist, with AAI and AAII being particularly nephrotoxic $(1,2)$. AA was originally used as a weight-loss supplement or for the treatment of snakebite, diarrhea and gynecological conditions (3). However, long-term use of agents containing AAI can lead to aristolochic acid nephropathy (AAN) or urothelial carcinoma $(2,4)$. AAN is an interstitial nephritis characterized by transient necrosis in its early stages and interstitial inflammation, fibrosis and tubular atrophy during its chronic phase (5). Effective therapies are needed to help improve the conditions of patients with AAN.

The mechanism of AAN initially involve apoptosis of proximal tubular epithelial cells (PTEC), followed by renal interstitial fibrosis. In addition, AAI is metabolized into intermediates that form covalent adducts with DNA, which leads to the blockage of DNA replication, inducing cell cycle arrest in the $\mathrm{G}_{2}$ phrase or cell apoptosis (6,7). AAI itself can cause apoptosis by activating the p53 signaling pathway, with AAI being especially pro-apoptotic (6). Renal interstitial fibrosis also accelerates the development of AAN, as indicated by increased expression of bone morphogenetic protein-7 (8), transforming growth factor- $\beta$ (9) and reduced levels of matrix metalloproteinase-9 (10).

The mTOR signaling pathway serves a critical role in tissue fibrosis due to its ability to catalyze cell proliferation and protein synthesis, which are also associated with cell cycle progression $(11,12)$. Rapamycin functions as an inhibitor of the mTOR signaling pathway by binding with FK506-binding protein 12 and mTOR complex 1 (13). This causes inhibition of the bioactivities of mTOR, including regulation of proliferation, differentiation, growth and transference of cells (14-16).

The present study was designed to investigate whether rapamycin has therapeutic effects on chronic aristolochic acid 
nephropathy (CAAN). For the in vitro experiments, the HK-2 cell line was used to examine the influence of rapamycin on cell cycle arrest and apoptosis. Murine in vivo experiments were also conducted, whereby analysis of urea nitrogen and creatinine, and hematoxylin and eosin (H\&E) staining of renal tissue determined whether the damage to kidney function structure induced by AAI could be reversed by rapamycin treatment. It was hypothesized that any ameliorative effects would be facilitated through the mTOR signaling pathway, which were observed as reduction in the expression of genes associated with cell apoptosis, proliferation and fibrosis.

\section{Materials and methods}

\section{In vitro experiments}

Cell culture. Rapamycin was purchased from MedChemExpress. HK-2 cells were purchased from Kunming Cell Bank, Chinese Academy of Sciences and cultured in DMEM (Gibco; Thermo Fisher Scientific, Inc.) supplemented with 10\% FBS (Gibco; Thermo Fisher Scientific, Inc.) in a $5 \% \mathrm{CO}_{2}$ incubator at $37^{\circ} \mathrm{C}$. Cells used for in vitro experiments were divided into three groups at $1 \times 10^{5}$ cells/well: Untreated group (control group), cells dosed with $10 \mu \mathrm{g} / \mathrm{ml} \mathrm{AAI}$ (AAI group) and AAI cells treated with rapamycin (RMS; AAI + RMS). The dosage used was based on a previous study $(17,18)$, which used 50 and $100 \mathrm{nM}$ rapamycin for $24 \mathrm{~h}$. Since no difference in morphology was found in cells treated with 50 and $100 \mathrm{nM} \mathrm{AAI}, 50 \mathrm{nM}$ was used for subsequent experiments. Cells in the control group were grown in DMEM, while the AAI + RMS group was pre-treated with 50 and $100 \mathrm{~nm}$ rapamycin for $24 \mathrm{~h}$. Cells in the AAI and treatment groups were dosed with $10 \mu \mathrm{g} / \mathrm{ml}$ AAI (Sigma Aldrich; Merck $\mathrm{KGaA}$ ) for $24 \mathrm{~h}$ to induce injury. Cell morphological changes were observed under an light microscope (S800T-950HK; Leica Microsystems $\mathrm{GmbH}$ ) after $48 \mathrm{~h}$.

Flow cytometry. A cell cycle staining kit [Multi Sciences (Lianke) Biotech Co., Ltd.] was used to analyze the cell cycle. A total of $2 \times 10^{6}$ cells were washed with $3 \mathrm{ml}$ of $1 \mathrm{X}$ PBS. Subsequently, $10 \mu 1$ permeabilization solution and $1 \mathrm{ml}$ DNA staining solution were incubated with the cells at room temperature for $30 \mathrm{~min}$. The cells were then detected by flow cytometry. An Annexin V-FITC/propidium iodide (PI) apoptosis kit [Multi Sciences (Lianke) Biotech Co., Ltd.] was used to detect cell apoptosis. A total of $2 \times 10^{6}$ cells were suspended in $500 \mu 1$ of binding buffer. Each sample was then incubated with $5 \mu \mathrm{l}$ Annexin V-FITC and $10 \mu \mathrm{l}$ PI at room temperature in the dark for $5 \mathrm{~min}$. Apoptotic cells were subsequently analyzed using a flow cytometer coupled with the FlowJo software (version 7.6; FlowJo LLC).

\section{In vivo experiments}

Mice and treatment. A total of 608 -week-old specific pathogen free grade C57BL/6 male mice weighing 25-30 g were purchased from the Experimental Animal Center of Wenzhou Medical University [SCXK (Zhe) 2015-0001, Wenzhou, China]. Animal procedures were based on international guidelines and approved by The Wenzhou Medical University Animal Policy and Welfare Committee (approval no. wydw 2014-0066). All mice were housed in controlled conditions, at $24 \pm 1^{\circ} \mathrm{C}$ and $50 \pm 1 \%$ relative humidity, a 12 -h light/dark cycle and had free access to food and water. Mice were randomly divided into three different groups: Control group $(n=20)$, CAAN group $(n=20)$ and treatment group $(n=20)$. A CAAN mouse model was constructed through reiterative intraperitoneal injection of AAI (dissolved in PBS supplemented with $0.15 \%$ DMSO) at a dose of $5 \mathrm{mg} / \mathrm{kg} /$ every two days for 6 consecutive weeks. Simultaneously, rapamycin (Selleck Chemicals) was administered to the treatment group by intraperitoneal injection at a dose of $1 \mathrm{mg} / \mathrm{kg} / \mathrm{day}$ for 6 consecutive weeks. The normal control group was injected with the same volume of normal saline over the same 6-week period. Blood and kidney tissues were collected for analysis.

Tissue sampling. All mice were exposed to isoflurane sustained at $5 \%$ for $\sim 2 \mathrm{~min}$ in a ventilator. Mice were then sacrificed by vertebral dislocation. Blood was collected from the orbital veins for quantification of creatinine and urea nitrogen. Both kidneys were obtained from each mouse and subsequently divided into two sections. One section was cut into small cubes and frozen at $-80^{\circ} \mathrm{C}$ for later protein analysis, and the remaining section was used for histopathological staining. Tissue for staining was first fixed in $4 \%$ PFA for $\geq 72 \mathrm{~h}$ at room temperature, then embedded in paraffin, dehydrated and cut into $5 \mu \mathrm{m}$-thick slices.

Histopathology and immunohistochemistry. Following deparaffinization and rehydration, the tissue slices were stained with $\mathrm{H} \& \mathrm{E}$ for general histopathological observation and assessment of parameters including tubular atrophy and glomerular structure. Subsequently, the presence of cell apoptosis, proliferation and fibrosis markers was assessed by immunohistochemical (IHC) staining. All paraffin tissue sections were dewaxed in xylene and rehydrated using a descending alcohol gradient. The sections were then processed with $3 \%$ hydrogen peroxide to block endogenous peroxidase, citrate buffer to retrieve antigen and $5 \%$ goat serum (Beyotime Institute of Biotechnology) at $37^{\circ} \mathrm{C}$ in an oven for $1 \mathrm{~h}$ to eliminate nonspecific binding sites. Samples were incubated with the following primary antibodies: Anti-Ki67 (1:200; cat. no. ab15580; Abcam), anti-cleaved caspase-3 (1:100; cat. no. ab2302; Abcam) and anti- $\alpha$-smooth muscle actin $\left(\alpha\right.$-SMA; cat. no. ab32575; 1:200) at $4^{\circ} \mathrm{C}$ overnight. The next day, the sections were incubated with horseradish peroxidase (HRP)-labeled Goat Anti-Rabbit IgG secondary antibodies (1:50; cat. no. A0208; Beyotime Institute of Biotechnology) at $37^{\circ} \mathrm{C}$ for $1 \mathrm{~h}$ and visualized using diaminobenzidine (brown staining; Beyotime Institute of Biotechnology). The intensity and area of positive staining was determined by measuring the integrated optical density (IOD)/area value using the Image-Pro Plus 6.0 image analysis software (Media Cybernetics, Inc.).

Western blot analysis. The specific method used for western blotting was described in a previous study (19). The kidney tissues were first homogenized with RIPA buffer supplemented with phosphatase inhibitors (Beyotime Institute of Biotechnology) extract the total protein. Protein concentration was determined with a bicinchoninic acid Protein Assay kit (Beyotime Institute of Biotechnology). The following primary antibodies were used at $4^{\circ} \mathrm{C}$ overnight on a shaking table: Proliferating cell nuclear antigen (PCNA; 1:1,000; cat. no. ab92552; Abcam), Bax (1:1,000; cat. no. ab32503; Abcam), Bcl-2 (1:1,000; cat. 
A

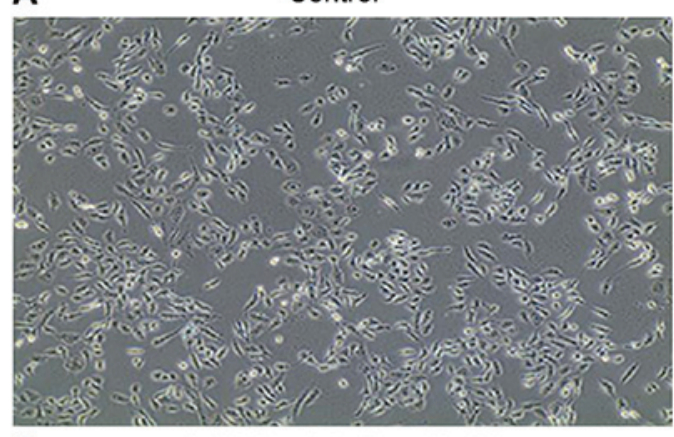

C

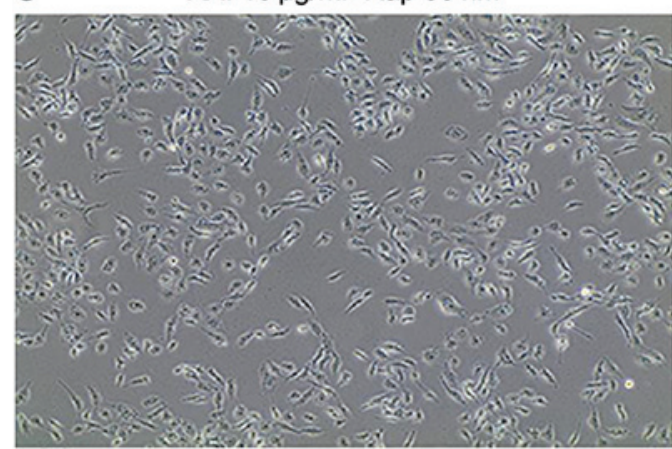

B

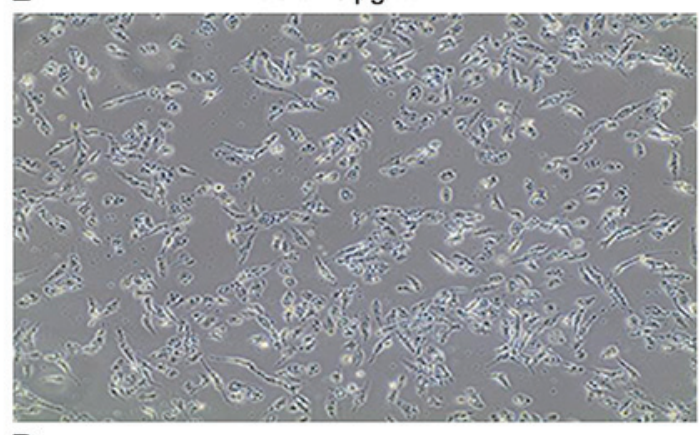

D AAI $10 \mu \mathrm{g} / \mathrm{ml}+$ Rap $100 \mathrm{nM}$

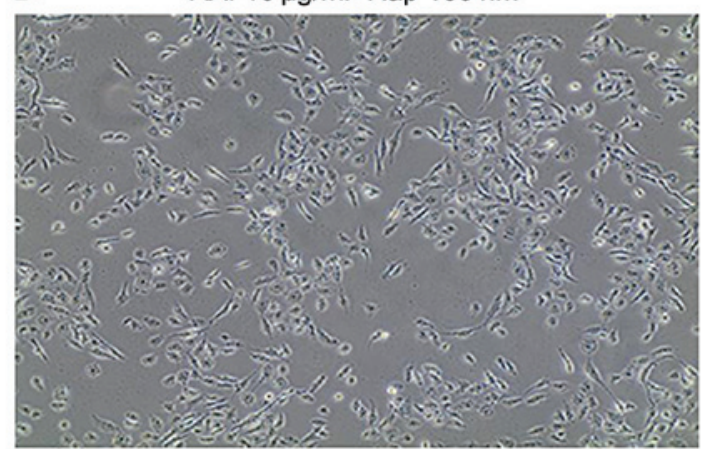

Figure 1. Morphological changes of HK-2 cells. (A) Image of normal control cells. (B) Image of HK-2 cells treated with $10 \mu \mathrm{g} / \mathrm{ml}$ AAI for $24 \mathrm{~h}$. (C) Image of cells pretreated with $50 \mathrm{~nm}$ rapamycin for $24 \mathrm{~h}$ and co-cultured with $10 \mu \mathrm{g} / \mathrm{ml} \mathrm{AAI}$ for $24 \mathrm{~h}$. (D) Image of cells pretreated with $100 \mathrm{~nm}$ rapamycin for $24 \mathrm{~h}$ and co-cultured with $10 \mu \mathrm{g} / \mathrm{ml}$ AAI for $24 \mathrm{~h}$. Magnification, x200. AAI, aristolochic acid; Rap, rapamycin.
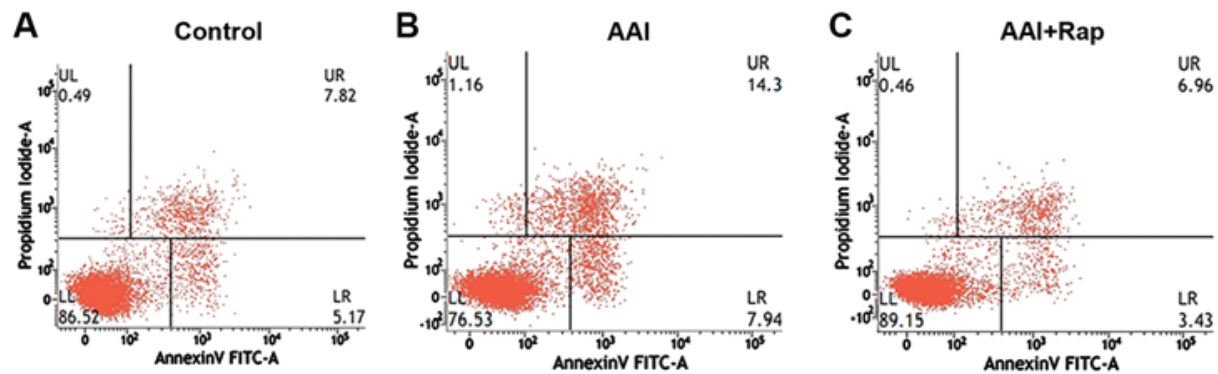

D

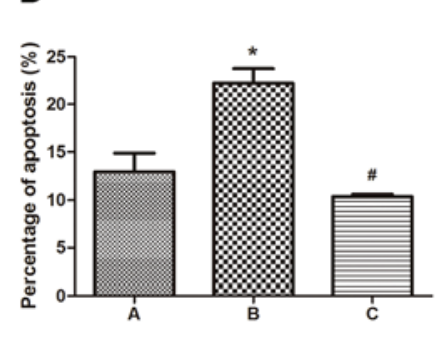

Figure 2. Comparison of cell apoptosis rates by flow cytometry. (A) Cell apoptosis rates in the control group (12.99 $\pm 1.88 \%$ ). (B) The AAI group has the highest apoptosis rate $(22.24 \pm 1.53 \%)$ among the three groups. (C) In the treatment group the apoptosis rate $(10.39 \pm 0.25 \%)$ is significantly decreased compared with the AAI group. (D) Quantified data from (A-C) indicating significant differences between the three groups. ${ }^{*} \mathrm{P}<0.05, \mathrm{Control}$ vs. CAAN group; ${ }^{\sharp} \mathrm{P}<0.05, \mathrm{CAAN}$ vs. treatment group. AAI, aristolochic acid; Rap, rapamycin.

no. ab182858; Abcam), epithelial cell interstitial transformation (EMT; 1:1,000; cat. no. ab32039; Abcam)-related protein, E-cadherin (1:1,000; cat. no. ab76055; Abcam) and m-TOR pathway proteins [phosphorylated (p)-mTOR (1:1,000; cat. no. 5536; Cell Signaling Technology, Inc.), mTOR (1:1,000; cat. no. 2983; Cell Signaling Technology, Inc.), p-AKT (1:1,000; cat. no. 4060; Cell Signaling Technology, Inc.) and AKT (1:1,000; cat. no. 4685; Cell Signaling Technology, Inc.)] with GAPDH antibody (1:2,000; cat. no. BS72410; Bioworld Technology, Inc.) used as an internal reference. The next day, the membranes were incubated with HRP-conjugated goat anti-Rabbit IgG (1:5,000; cat. no. BS13278; Bioworld Technology, Inc.) or goat anti-Mouse IgG (1:5,000; cat. no. BS12471; Bioworld Technology, Inc.) secondary antibodies at room temperature for 1-2 h. Protein bands were visualized using SuperSignal ${ }^{\mathrm{TM}}$ West Femto Maximum Sensitivity Substrate (Thermo Fisher Scientific, Inc.) and the density of the bands were detected by Gel-Pro Analyzer Image Analysis Software (version 4.0; Meyer Instruments).

Statistical analysis. Each experiment was performed at least three times. One-way ANOVA followed by Tukey's post hoc test was applied to evaluate differences between groups. Data were analyzed using SPSS 16.0 (SPSS, Inc.) and GraphPad Prism 5.0 (GraphPad Software, Inc.). $\mathrm{P}<0.05$ was considered to indicate a statistically significant difference.

\section{Results}

\section{In vitro experiments}

Morphological changes of HK-2 cells. As shown in Fig. 1, cells in the AAI group (Fig. 1B) changed from ovate to elongated shapes, whereas cells in the AAI + RMS group 
A

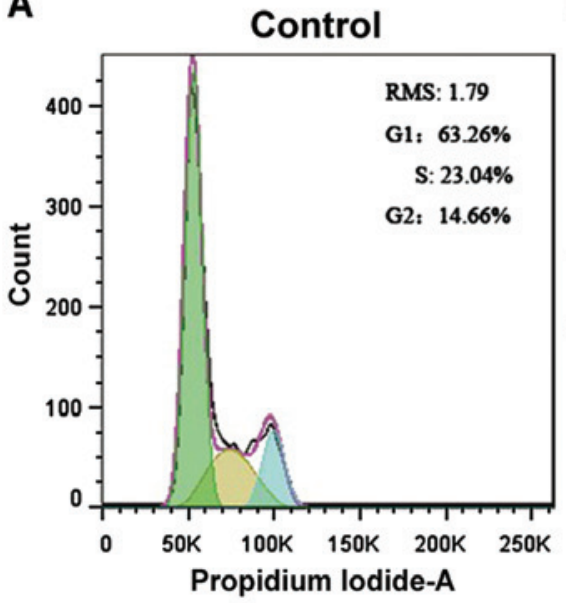

B

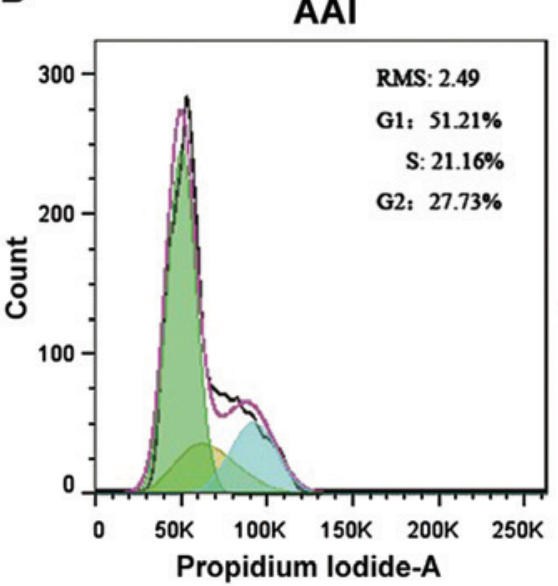

C

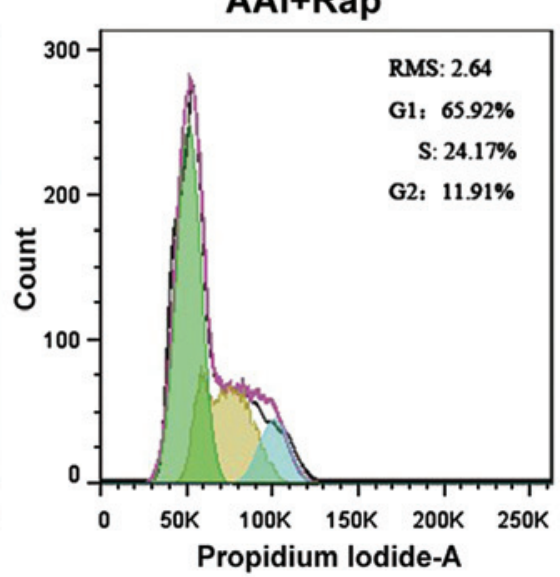

Figure 3. Variation in cell cycle progression. Cell cycle progression in the (A) control group, (B) AAI group and (C) AAI + RMS group. The green area represents the number of cells in the $\mathrm{G}_{1}$ phase, the yellow area represents the number of cells in the $\mathrm{S}$ phase and the blue area represents the number of cells in the $\mathrm{G}_{2}$ phase. AAI, aristolochic acid; RMS, rapamycin.

(Fig. 1C) developed smooth margins. Two doses (50 and $100 \mathrm{~nm}$ ) were initially used to determine the optimum concentration of rapamycin. However, little morphological difference was observed between these differently dosed groups (Fig. 1C and D). Therefore, $50 \mathrm{~nm}$ rapamycin was used for subsequent experiments.

Cell apoptosis and cell cycle alteration results were as follows. As shown in Fig. 2, the percentage of apoptotic cells was higher in the AAI group $(22.24 \pm 1.53 \%)$ and lower in the AAI + RMS group $(10.39 \pm 0.25 \%)$ compared with the control group $(12.99 \pm 1.88 \%)$. Cell cycle alteration was detected based on the amount of chromosomal ploidy present (Fig. 3). The proportion of cells in the $\mathrm{G}_{1}$ phase was $51.21 \%$ in the AAI group and $65.92 \%$ in the AAI + RMS group. The proportion of cells in the $\mathrm{G}_{2} / \mathrm{M}$ phase decreased from $27.73 \%$ in the AAI group to $11.91 \%$ in the AAI + RMS group. The results demonstrated that rapamycin can decrease apoptosis and prevent $\mathrm{G}_{2} / \mathrm{M}$ phase cell cycle arrest.

\section{In vivo experiments}

Therapeutic effects of rapamycin. As shown in Fig. 4, urea nitrogen and creatinine levels were highest in the CAAN group $(\mathrm{P}<0.05)$, which also indicated that $\mathrm{CAAN}$ mice models were successfully established. However, in the treatment group, these two indexes declined compared with the CAAN group, especially that of urea nitrogen $(\mathrm{P}<0.05)$. The observations corroborate pathological observations. As shown in Fig. 5, compared with the control group, the structure of kidney tissues in the CAAN group was damaged, with tubular atrophy and amplified interstitial fibrotic areas. In addition, glomeruli were barely visible in the whole tissue section. By contrast, treatment group tissues exhibited reduced tubular atrophy and larger areas of glomeruli.

Potential therapeutic effects of rapamycin. To confirm the therapeutic effects of rapamycin for alleviating kidney injuries induced by AAI, IHC staining was performed to determine the expression levels of molecules related to cell apoptosis, proliferation and tissue fibrosis (Fig. 6A and B). Areas positive

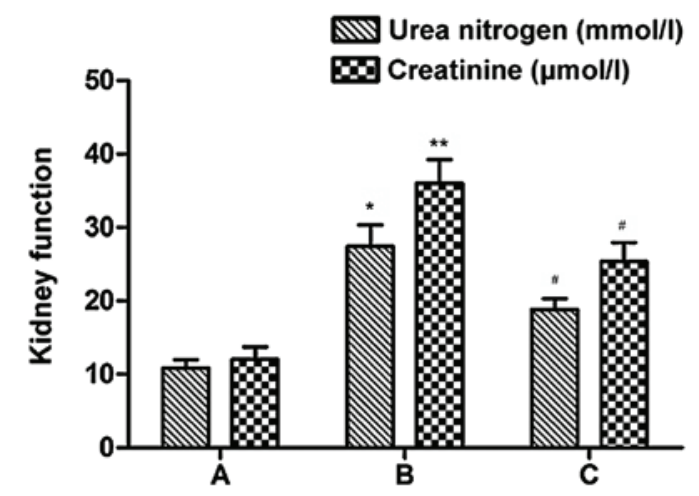

Figure 4. Kidney function index detection. Kidney function worsened in the CAAN group compared with the control group, but improved in the treatment group compared with the CAAN group. ${ }^{*} \mathrm{P}<0.05$ and ${ }^{* *} \mathrm{P}<0.01$ vs. Control and ${ }^{\#} \mathrm{P}<0.05$, CAAN vs. treatment. A, control group; B, CAAN group; C, treatment group; CAAN, chronic aristolochic acid nephropathy.

for $\alpha$-SMA, Ki 67 and cleaved-caspase 3 staining were clearly observed in the CAAN group (Fig. 6A), and the levels of these proteins were significantly increased compared with the control group (Fig. 6B; Ki 67, $\mathrm{P}<0.05$; cleaved caspase-3, $\mathrm{P}<0.01$; $\alpha$-SMA, $\mathrm{P}<0.01)$. However, following treatment with rapamycin, the number of positively-stained areas decreased (Fig. 6B; Ki 67, $\mathrm{P}<0.05$; cleaved caspase-3, $\mathrm{P}<0.05 ; \alpha$-SMA, $\mathrm{P}<0.05)$.

The western blotting results were in accordance with microscopic observations (Fig. 7B-D), where the expression of PCNA, Bax and $\alpha$-SMA were all elevated in the CAAN group, but reversed by treatment $(\mathrm{P}<0.01$ or $\mathrm{P}<0.05)$. In addition, the expression of anti-apoptotic $\mathrm{Bcl}-2$ and anti-fibrotic E-cadherin were both elevated in the treatment group but decreased in the CAAN group compared with the control group.

As shown in Fig. 7A, levels of mTOR and AKT phosphorylation were both elevated in the CAAN group but declined in the treatment group $(\mathrm{P}<0.01$ and $\mathrm{P}<0.05)$. Therefore, rapamycin may block the phosphorylation and subsequent activation of mTOR signaling, in turn resulting in the alleviation of cell proliferation, apoptosis and ultimately reduce tissue fibrosis. 

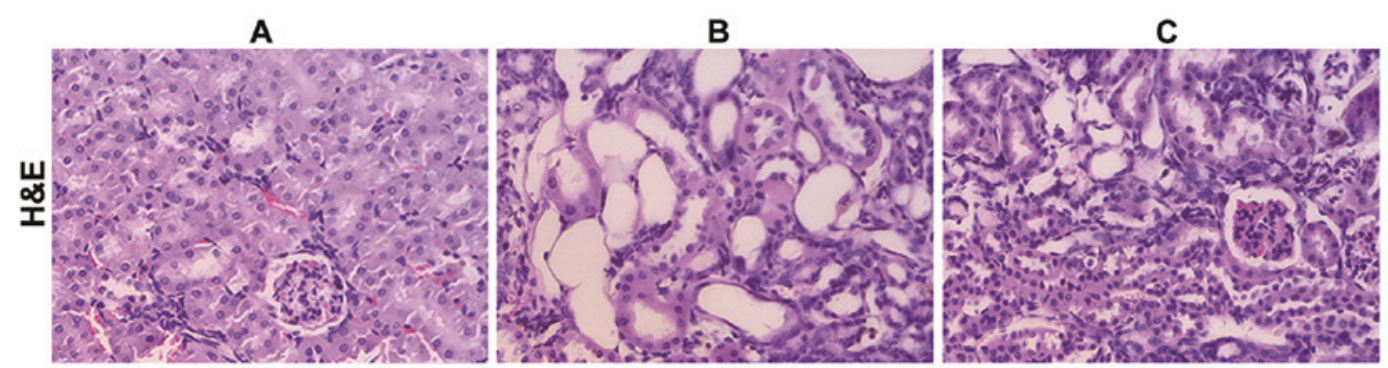

Figure 5. Changes in histopathology assessed by H\&E staining. Magnification, $\mathrm{x} 400$. H\&E, hematoxylin and eosin; A, control group; B, CAAN group; C, treatment group; CAAN, chronic aristolochic acid nephropathy.

A
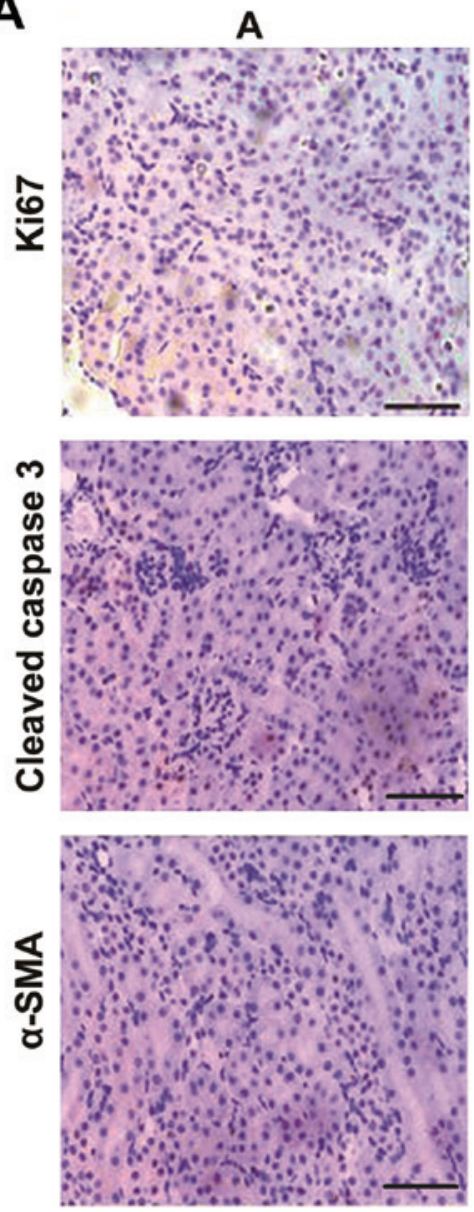

B
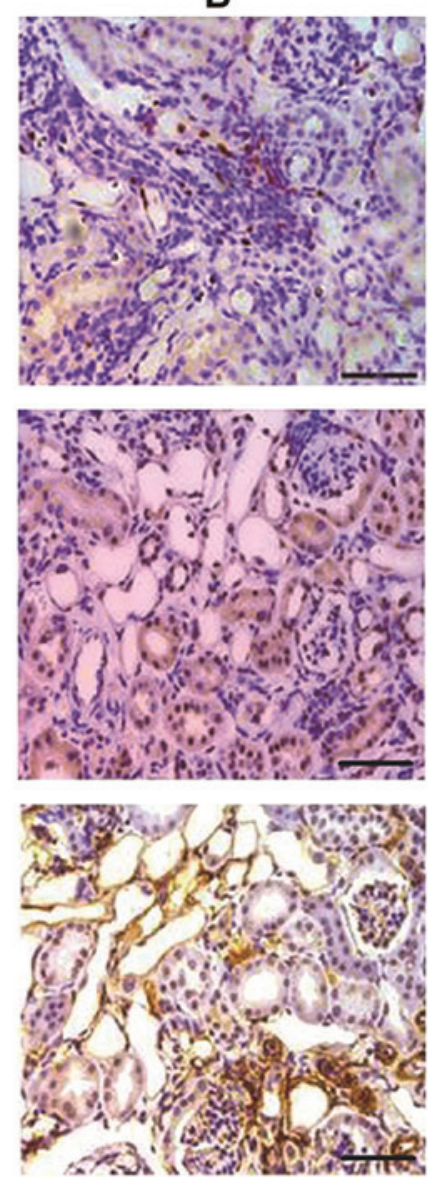

C
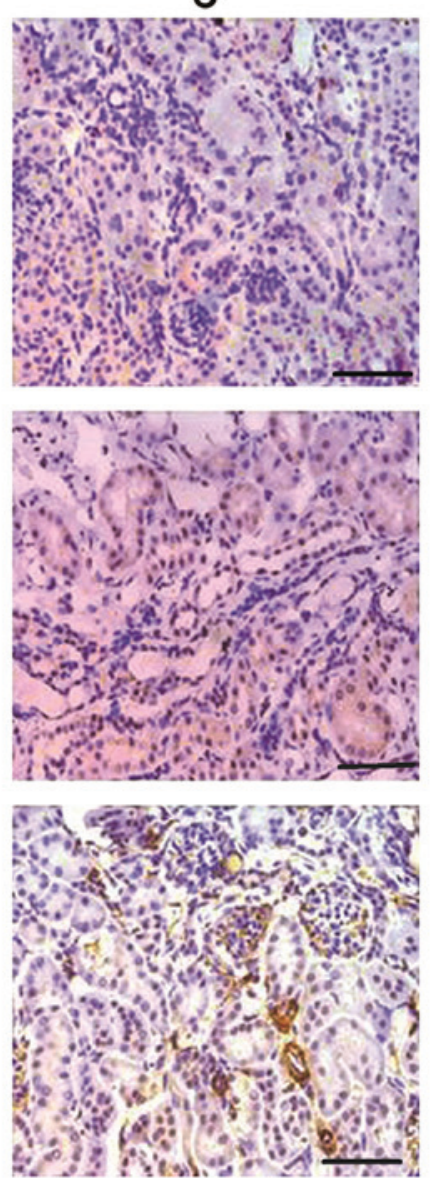

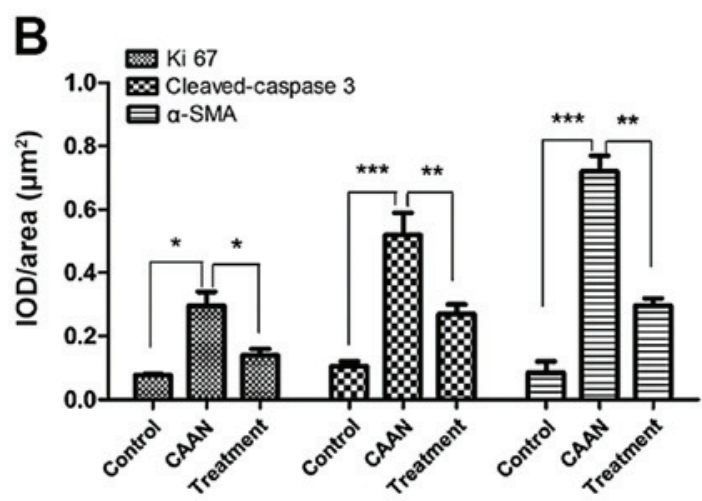

Figure 6. Expression of apoptosis-, proliferation- and fibrosis-related proteins. (A) Cleaved caspase-3, Ki67 and $\alpha$-SMA immunohistochemical staining. Brown color represents positive staining. (B) Measurement of the IOD/area of immunohistochemical staining of Ki67, cleaved caspase 3 and $\alpha$-SMA. ${ }^{* * *} \mathrm{P}<0.001$, ${ }^{* *} \mathrm{P}<0.01,{ }^{*} \mathrm{P}<0.05$. Scale bar, $50 \mu \mathrm{m}$. Ki67, proliferation marker protein Ki67; $\alpha$-SMA, $\alpha$-smooth muscle actin; CAAN, chronic aristolochic acid nephropathy; IOD, integrated optical density; A, control group; B, CAAN group; C, treatment group. 

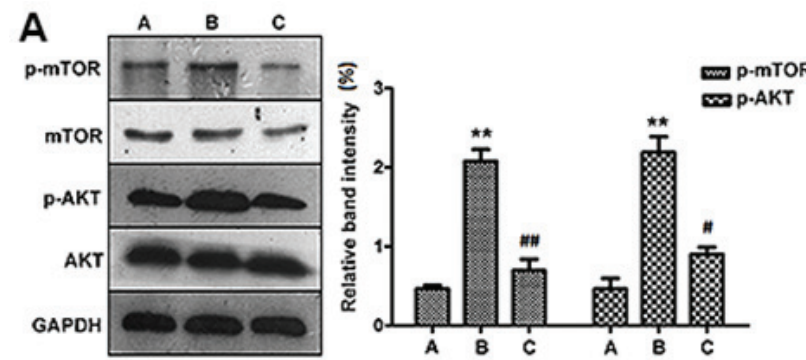

C
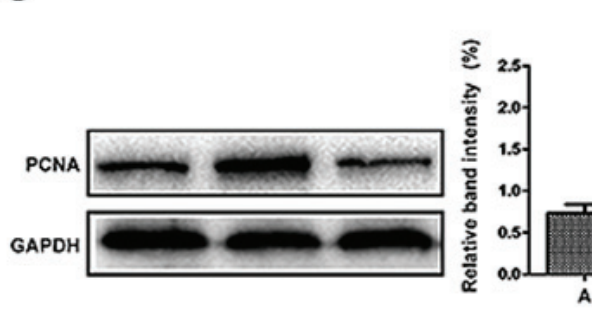

PCNA

(n)
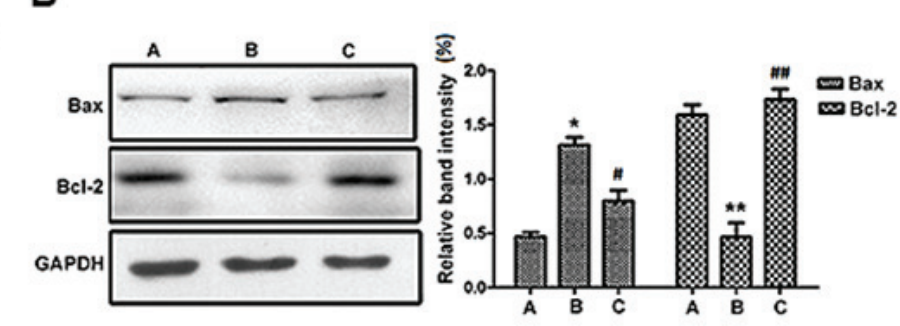

D
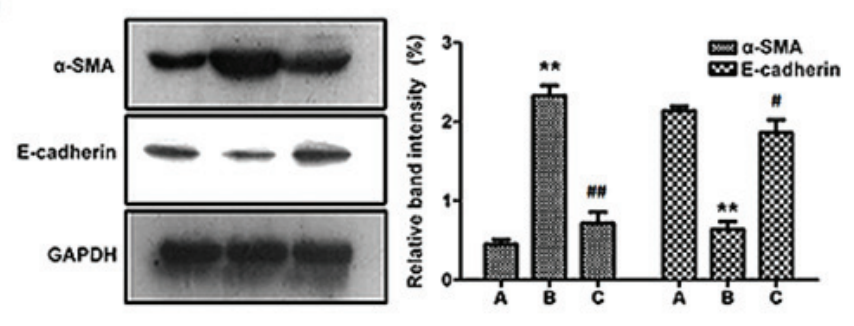

Figure 7. Western blotting results. (A) Expression levels of key proteins in the mTOR signaling pathway. The expression of p-AKT and p-mTOR increased in the CAAN group and decreased in the treatment group. Expression levels of (B) Bax and Bcl-2, (C) PCNA, (D) $\alpha-S M A$ and E-cadherin. "P<0.05 and ${ }^{* *} \mathrm{P}<0.01$ vs. control; ${ }^{~} \mathrm{P}<0.05$ and ${ }^{\# \#} \mathrm{P}<0.01$ vs. CAAN. A, control group; B, CAAN group; C, treatment group; p-AKT, phospho-AKT; p-mTOR, phospho-mTOR; CAAN, chronic aristolochic acid nephropathy; PCNA, proliferating cell nuclear antigen; $\alpha$-SMA, $\alpha$-smooth muscle actin.

\section{Discussion}

AAN is a long-term chronic disease which causes irreversible structural injury and leaves patients with a poor quality of life $(20,21)$. However, the progression of AAN cannot be prevented in most patients (22). The present research was performed to investigate the ameliorative effects and mechanism of action of rapamycin on AAN.

The in vitro experiments included in the current study showed that abnormal cell shape, apoptosis and cell cycle arrest at the $\mathrm{G}_{2} / \mathrm{M}$ checkpoint were clearly observed in the CAAN group. The $\mathrm{G}_{2} / \mathrm{M}$ checkpoint is a control point used by cells to protect against injury, as it allows termination of genotoxicity (23) and also enables epithelial cells to transdifferentiate (24). Thus, if an organism detects DNA damage in response to injury, cell cycle progression is inhibited and DNA-damage repair is activated (25). However, the $\mathrm{G}_{2} / \mathrm{M}$ checkpoint is the last defense for DNA repair; if damage cannot be repaired then, cell death will be induced (26). In the CAAN group, a high proportion of the cell population in the $\mathrm{G}_{2}$ phase indicated that extensive DNA damage had occurred and increased the possibility of cell apoptosis. Furthermore, apoptosis enables cells to change from an epithelial type to a fibroblast type, while cell cycle arrest provides cells with the opportunity to transform into fibroblast types, which are more likely to survive injury (24).

The in vivo experiments showed that rapamycin was, to a certain extent, able to improve impaired kidney function and reverse damaged kidney structures such as tubular dilation and interstitial fibrosis. The expression of p-mTOR and p-AKT both declined in the treatment group, which indicated that the mTOR signaling pathway had been successfully blocked by rapamycin. Furthermore, the expression levels of apoptosis-, cell proliferation- and tissue fibrosis-related proteins were all decreased in the treatment group.
The present results show the possible therapeutic effects of rapamycin on CAAN. Rapamycin has also been used for other disease research, such as immunoglobulin A nephropathy, obstructive nephropathy, diabetic nephropathy and kidney neoplasms (27-29). These diseases have common pathological features such as cell apoptosis, proliferation and tissue fibrosis, thus, they may also be seen as functional targets of rapamycin. Rapamycin is an mTOR inhibitor and the upstream regulator of mTOR-like serine/threonine kinase AKT and ERK1/2, which are responsible for extracellular matrix synthesis and cell proliferation $(30,31)$. This can account for the decreased levels of cell proliferation and fibrosis observed in the treatment group.

The apoptosis of tubular epithelial cells is crucial for nephron destruction (32). Rapamycin also directly interferes with apoptosis by inhibiting the mTOR signaling pathway. mTOR plays an important role in phosphorylating/inactivating $\mathrm{Bcl}-2$ and increasing the expression of caspase $3(33,34)$. Another previous study stated that rapamycin can interrupt mTOR-triggered transformation of the nucleus, and block the transcription of p53 and triggering of cell apoptosis (34). Thus, proapoptotic proteins such as Bax can be depleted, as was reflected in the present research, with western blotting and immunohistochemical staining confirming that Bax and cleaved caspase-3 levels declined following treatment with rapamycin.

The present study primarily analyzed the ameliorative effects of rapamycin through cell apoptosis, proliferation and tissue fibrosis. When cells are injured, proliferation can be activated to compensate for high levels of apoptosis (24). However, the newly proliferated cells can become hypersensitive to injury factors (35-37), which can lead to further apoptosis, and eventually result in the further aggravation of injury, forming a vicious cycle of cell apoptosis-proliferation. However, treatment with rapamycin can inhibit the mTOR signaling pathway and thus prevent cell death. 
There are some limitations in the present study. In the in vitro experiments, the dosages of AAI and rapamycin were determined by referring to published results. Dosages would be better determined by performing Cell Counting Kit- 8 or real time cell analysis assays. The effects of rapamycin provided by different suppliers should also be tested. For the in vivo experiments, only mTOR signaling pathway proteins were examined. Furthermore, the molecular mechanisms associated with apoptosis, proliferation and fibrosis need to be studied in more detail. The rate of cell proliferation and sensitivity to injuries should also be taken into consideration.

In conclusion, the present findings confirm that rapamycin can improve CAAN symptoms in vitro and in a mouse model by blockade of the mTOR signaling pathway, leading to a decrease in cell apoptosis, proliferation and fibrosis. Therefore, rapamycin should be investigated as a possible new therapeutic strategy for the treatment of CAAN.

\section{Acknowledgements}

Not applicable.

\section{Funding}

This study was supported by grants from The Natural Science Foundation of Zhejiang Province (grant no. LY14H050006), The National Natural Science Foundation of China (grant no. 8157080113), The Natural Science Foundation of Shenzhen University General Hospital (grant no. SUGH2018QD071), and The Natural Science Foundation of Shenzhen University General Hospital (grant no. SUGH2018QD013).

\section{Availability of data and materials}

The datasets used and/or analyzed during the present study are available from the corresponding author on reasonable request.

\section{Authors' contributions}

MMW performed most of the animal experiments, including establishment of CAAN mice, H\&E and IHC staining. FL helped to design and guide the study. LLT and FQD performed all western blot anlaysis and flow cytometry experiments. JJZ, ZS and BCC were responsible for data analysis. MMW and FL drafted the manuscript. All authors read and approved the final manuscript.

\section{Ethics approval and consent to participate}

This study was approved by The Ethics Committee of the First Affiliated Hospital of Wenzhou Medical University (grant no. wydw2014-0066; Wenzhou, China).

\section{Patient consent for publication}

Not applicable.

\section{Competing interests}

The authors declare that they have no competing interests

\section{References}

1. Vanherweghem JL, Depierreux M, Tielemans C, Abramowicz D, Dratwa M, Jadoul M, Richard C, Vandervelde D, Verbeelen D, Vanhaelen-Fastre R, et al: Rapidly progressive interstitial renal fibrosis in young women: Association with slimming regimen including Chinese herbs. Lancet 341: 387-391, 1993.

2. Nortier JL, Martinez MC, Schmeiser HH, Arlt VM, Bieler CA, Petein M, Depierreux MF, De Pauw L, Abramowicz D, Vereerstraeten P and Vanherweghem JL: Urothelial carcinoma associated with the use of a Chinese herb (Aristolochia fangchi). N Engl J Med 342: 1686-1692, 2000.

3. Heinrich M, Chan J, Wanke S, Neinhuis C and Simmonds MS: Local uses of Aristolochia species and content of nephrotoxic aristolochic acid 1 and 2-a global assessment based on bibliographic sources. J Ethnopharmacol 125: 108-144, 2009.

4. Hamano Y, Aoki T, Shirai R, Hatano M, Kimura R, Ogawa M, Yokosuka O and Ueda S: Low-dose darbepoetin alpha attenuates progression of a mouse model of aristolochic acid nephropathy through early tubular protection. Nephron Exp Nephrol 114: e69-e81, 2010.

5. Pozdzik AA, Salmon IJ, Husson CP, Decaestecker C, Rogier E, Bourgeade MF, Deschodt-Lanckman MM, Vanherweghem JL and Nortier JL: Patterns of interstitial inflammation during the evolution of renal injury in experimental aristolochic acid nephropathy. Nephrol Dial Transplant 23: 2480-2491, 2008.

6. Zhou L, Fu P, Huang XR, Liu F, Lai KN and Lan HY: Activation of p53 promotes renal injury in acute aristolochic acid nephropathy. J Am Soc Nephrol 21: 31-41, 2010.

7. Arlt VM, Stiborova M and Schmeiser HH: Aristolochic acid as a probable human cancer hazard in herbal remedies: A review. Mutagenesis 17: 265-277, 2002.

8. Li Y, Wang Z, Wang S, Zhao J, Zhang J and Huang Y: Gremlin-mediated decrease in bone morphogenetic protein signaling promotes aristolochic acid-induced epithelial-to-mesenchymal transition (EMT) in HK-2 cells. Toxicology 297: 68-75, 2012.

9. Rui HL, Wang YY, Cheng H and Chen YP: JNK-dependent AP-1 activation is required for aristolochic acid-induced TGF- $\beta 1$ synthesis in human renal proximal epithelial cells. Am J Physiol Renal Physiol 302: F1569-F1575, 2012.

10. Wu CJ, Chou YC, Cheng YW, Hsiao CJ, Wang CH, Wang HY, Sheu JR and Hsiao G: Aristolochic acid downregulates monocytic matrix metalloproteinase- 9 by inhibiting nuclear factor- $\kappa \mathrm{B}$ activation. Chem Biol Interact 192: 209-219, 2011.

11. Hartford CM and Ratain MJ: Rapamycin: Something old, something new, sometimes borrowed and now renewed. Clin Pharmacol Ther 82: 381-388, 2007.

12. Hay N and Sonenberg N: Upstream and downstream of mTOR. Genes Dev 18: 1926-1945, 2004.

13. Wang $X$ and Proud CG: mTORC1 signaling: What we still don't know. J Mol Cell Biol 3: 206-220, 2011.

14. Laplante M and Sabatini DM: mTOR signaling in growth control and disease. Cell 149: 274-293, 2012.

15. Burnett PE, Barrow RK, Cohen NA, Snyder SH and Sabatini DM: RAFT1 phosphorylation of the translational regulators p70 S6 kinase and 4E-BP1. Proc Natl Acad Sci USA 95: 1432-1437, 1998.

16. Brown EJ, Beal PA, Keith CT, Chen J, Shin TB and Schreiber SL. Control of p70 s6 kinase by kinase activity of FRAP in vivo. Nature 377: 441-446, 1995.

17. Li J, Zhang M, Mao Y, Li Y, Zhang X, Peng X and Yu F: The potential role of aquaporin 1 on aristolochic acid I induced epithelial mesenchymal transition on HK-2 cells. J Cell Physiol 233: 4919-4925, 2018.

18. Kan WC, Hwang JY, Chuang LY, Guh JY, Ye YL, Yang YL and Huang JS: Effect of osthole on advanced glycation end products-induced renal tubular hypertrophy and role of klotho in its mechanism of action. Phytomedicine 53: 205-212, 2019.

19. Zhou Q, Du J, Hu Z, Walsh K and Wang XH: Evidence for adipose-muscle cross talk: Opposing regulation of muscle proteolysis by adiponectin and Fatty acids. Endocrinology 148: 5696-5705, 2007.

20. Dickman KG, Sweet DH, Bonala R, Ray $\mathrm{T}$ and $\mathrm{Wu} A$ : Physiological and molecular characterization of aristolochic acid transport by the kidney. J Pharmacol Exp Ther 338: 588-597, 2011.

21. Ma DH, Zheng FL, Su Y, Li MX and Guo MH: Influence and analysis of low-dosage steroid therapy in severe aristolochic acid nephropathy patients. Nephrology (Carlton) 21: 835-840, 2016. 
22. Luciano RL and Perazella MA: Aristolochic acid nephropathy: Epidemiology, clinical presentation, and treatment. Drug Saf 38: 55-64, 2015.

23. Stark GR and Taylor WR: Analyzing the G2/M checkpoint. Methods Mol Biol 280: 51-82, 2004.

24. Yang L, Besschetnova TY, Brooks CR, Shah JV and Bonventre JV: Epithelial cell cycle arrest in G2/M mediates kidney fibrosis after injury. Nat Med 16: 535-543, 2010.

25. Buisson R, Niraj J, Rodrigue A, Ho CK, Kreuzer J, Foo TK, Hardy EJ, Dellaire G, Haas W, Xia B, et al: Coupling of homologous recombination and the checkpoint by ATR. Mol Cell 65: 336-346, 2017.

26. Visconti R, Della Monica R and Grieco D: Cell cycle checkpoint in cancer: A therapeutically targetable double-edged sword. J Exp Clin Cancer Res 35: 153, 2016.

27. Wu MJ, Wen MC, Chiu YT, Chiou YY, Shu KH and Tang MJ: Rapamycin attenuates unilateral ureteral obstruction-induced renal fibrosis. Kidney Int 69: 2029-2036, 2006.

28. Tian J, Wang Y, Liu X, Zhou X and Li R: Rapamycin ameliorates IgA nephropathy via cell cycle-dependent mechanisms. Exp Biol Med (Maywood) 240: 936-945, 2015.

29. Velagapudi C, Bhandari BS, Abboud-Werner S, Simone S, Abboud HE and Habib SL: The tuberin/mTOR pathway promotes apoptosis of tubular epithelial cells in diabetes. J Am Soc Nephrol 22: 262-273, 2011.

30. Liu DD, Han CC, Wan HF, He F, Xu HY, Wei SH, Du XH and Xu F: Effects of inhibiting PI3K-Akt-mTOR pathway on lipid metabolism homeostasis in goose primary hepatocytes. Animal 10: 1319-1327, 2016.
31. Zeng R, Xiong Y, Zhu F, Ma Z, Liao W, He Y, He J, Li W, Yang J, Lu Q, et al: Fenofibrate attenuated glucose-induced mesangial cells proliferation and extracellular matrix synthesis via PI3K/AKT and ERK1/2. PLoS One 8: e76836, 2013.

32. Johnson A and DiPietro LA: Apoptosis and angiogenesis: An evolving mechanism for fibrosis. FASEB J 27: 3893-3901, 2013.

33. Calastretti A, Bevilacqua A, Ceriani C, Viganò S, Zancai P, Capaccioli S and Nicolin A: Damaged microtubules can inactivate BCL-2 by means of the mTOR kinase. Oncogene 20: 6172-6180, 2001.

34. Cory S and Adams JM: The Bcl2 family: Regulators of the cellular life-or-death switch. Nat Rev Cancer 2: 647-656, 2002.

35. Shen YL, Sun L, Hu YJ, Liu HJ, Kuang XY, Niu XL and Huang WY: P53 inhibitor pifithrin-alpha prevents the renal tubular epithelial cells against injury. Am J Transl Res 8: 4040-4053, 2016.

36. Bonventre JV: Dedifferentiation and proliferation of surviving epithelial cells in acute renal failure. J Am Soc Nephrol 14 (Suppl 1): S55-S61, 2003.

37. Gniadecki R, Hansen M and Wulf HC: Two pathways for induction of apoptosis by ultraviolet radiation in cultured human keratinocytes. J Invest Dermatol 109: 163-169, 1997.

This work is licensed under a Creative Commons

Attribution-NonCommercial-NoDerivatives 4.0 International (CC BY-NC-ND 4.0) License. 